\title{
Las fronteras de los virreinatos imaginadas y vividas: propuestas para relecturas del mundo misional y su época a través de diarios de viajes de exploración, cartas edificantes y cartas personales \\ Images and Experiences of Viceroyalties' Frontiers: Propositions for Re-readings of the Missionary World and Its Times through Explorations Log-books, Edifying Letters and Personal Correspondence
}

\section{Mirjana Polić Bobić}

Universidad de Zagreb

CROACIA

mpolicbobic@gmail.com

[Hipogrifo, (issn: 2328-1308), 4.1, 2016, pp. 87-101]

Recibido: 15-12-2015 / Aceptado: 13-01-2016

DOI: http://dx.doi.org/10.13035/H.2016.04.01.06

Resumen. En este trabajo se propone la relectura de tres tipos de escritos practicados por los misioneros jesuitas en el Nuevo Mundo en los siglos XVII y XVIII en que ellos refieren sus experiencias de misioneros y exploradores, así como sus actitudes personales y sentimientos íntimos. La relectura de las prácticas discursivas en cuestión se propone a partir de la convicción de que el testimonio sobre el mundo misional referido en ellas puede enriquecer decisivamente la imagen del mismo, ya existente en el gran narrativo histórico.

Palabras clave. Prácticas discursivas, misioneros jesuitas, literatura colonial, imaginario, gran narrativo histórico. 
Abstract. In this paper we propose a re-reading of three types of texts in which the 17th and 18th century Jesuit missionaries in the New World described their experiences as missionaries as well as explorers, but also their personal views and feelings. We expect that such re-readings of their testimonies of the work and life in the missions would help build a richer and more complex image of the missionary life than that based on the grand narrative.

Keywords. Discoursive Pratices, Jesuit Missionaries, Colonial Literature, Imagery, Grand Narrative.

\section{INTRODUCCIÓN}

Los estudios de literatura y cultura coloniales de los últimos años se interesan cada vez más en las prácticas discursivas que en su época tuvieron posición marginal. Se trata de escritos u otros productos culturales de que se solía echar mano en cuanto que fuentes secundarias en la investigación de segmentos específicos del conjunto de la sociedad y cultura coloniales.

No sería exacto explicar esta tendencia exclusivamente por cierto cansancio con los temas que han formado el «mainstream» en nuestra percepción del mundo colonial o con los grandes narrativos históricos y los estudios de las bellas letras que mutuamente se apoyan. Al contrario: la tendencia se entiende como fruto de la convicción de que ampliando la tipología de fuentes, o formas discursivas, que ofrecen una visión más rica del conjunto de la vida cultural y social de un tiempo, y dejando de apreciarlas tan solo como fuentes de datos cuantitativos, resulta más completa la imagen de ese tiempo pasado. Es a partir de allí que los grandes narrativos puedan ser repensados y reescritos.

En su «Introducción» al tercer tomo de la nueva Historia de la literatura mexicana coordinada por Beatriz Garza Cuarón, y que termina con una invitación indirecta a su investigación, Nancy Vogeley define de la siguiente forma la acepción bastante modificada de literatura, acepción que forma parte de dicha tendencia:

Antes equivalente a las bellas artes, a las obras con parentesco en el pasado, a las actividades de una élite de escritores y lectores, recientemente se ha extendido el concepto para abarcar el conjunto de formas escriturarias y discursivas practicadas en un país en un momento determinado?.

En este trabajo se intentará proponer una de las posibles relecturas de los escritos producidos en las misiones que la Compañía de Jesús organizó y mantuvo en los vastos espacios fronterizos de los virreinatos ultramarinos a lo largo de dos siglos (XVII y XVIII) en cuanto que «formas discursivas» mencionadas en un sentido muy amplio. Aunque por la diversidad que presentan desde el punto de vista de la forma son de difícil clasificación, para este propósito los agrupamos en tres unidades: diarios de exploraciones encargados por la Compañía y la Corona, descripciones sumarias redactadas mayormente también por encargos (a menudo

1. Vogeley, 2011, p. 22

HIPOGRIFO, 4.1, 2016 (pp. 87-101) 
siguiendo un cuestionario), y cartas edificantes así como cartas personales. Se las presentará desde el punto de vista de algunas relecturas actuales del conjunto del espacio en que fueron redactadas y se formularán propuestas de su relectura a la luz de estas relecturas del conjunto.

A pesar de que unas (diarios, descripciones, cartas edificantes) se escribían para ser publicadas en forma de textos autónomos o bien incluidas en redacciones más extensas y ambiciosas, y las otras (cartas personales) por regla estaban destinadas tan solo a la comunicación personal, lo que tienen en común es la comunicación de las experiencias concretas, pormenorizadas y realistas (independientemente del tono de que las revestían sus autores) de la vida en la misión como frontera civilizacional y a la vez espacio de interculturalidad, tema tan interesante en aquel entonces como hoy en día, aunque por distintas razones.

\section{DISCURSO MARGINAL: DESMENUZAMIENTO Y PORMENOR POR OPOSICIÓN A LA SOLI- DEZ DEL GRAN NARRATIVO}

El cuerpo de escritos que la Compañía de Jesús dejó en base al conjunto de conocimientos y del saber que produjeron y recopilaron sus miembros en el Nuevo Mundo es desde todo punto monumental. El mismo representa también una fuente fidedigna para la investigación de los períodos pre-misionales (lo cual equivale a la situación precolonial dado que las misiones se establecían en territorios antes casi no tocados por la colonización ibérica) así como de lo colonial, en primer lugar (pero no exclusivamente), lo misional. En las grandes historias generales o especializadas, en informes anuales (litterae annuae o cartas anuas), en las síntesis que abarcan décadas e incluso siglos de presencia misional en una provincia, están presentados los grandes conjuntos sociales, culturales o históricos de la época en cuestión, así como distintos aspectos de los mismos, en la mayor parte de los casos también en sus dimensiones diacrónicas, incluyendo las reconstrucciones de la historia basadas en las investigaciones entonces hechas por los miembros de la orden en fuentes disponibles. Son grandes síntesis del conjunto del saber, a menudo con un propósito subyacente y expresado de manera más o menos oblicua. Al mismo tiempo, representan una evidencia de cómo el proyecto de las misiones en un espacio dado fue formando una sociedad que se imaginaba como ejemplar y que representaba la meta de ese proyecto.

Aunque lleve el nombre de un autor o compilador, este gran narrativo de la Compañía para las Américas de hecho equivalía al trabajo conjunto de varios, o incluso muchos autores: aquellos miembros de la Compañía que gracias al puesto que desempeñaban dentro de ella, podían proporcionar información, descripción, opinión, estimación etc., fidedignas que equivalían a su propia experiencia o eran resultado de su propia exploración u observación del terreno. La transmisión de esa experiencia formaba parte de sus obligaciones y fue en base al conjunto de tales experiencias que se redactaban las grandes síntesis. Daremos un ejemplo: para presentar el conjunto de los conocimientos sobre Baja California, tema intrigante desde el punto de vista de su geografía todavía a finales del siglo XVIII (y no 
exento de la carga que sobre él ejercía el imaginario heredado de Europa medieval y del siglo XVI ultramarino²), el padre Clavigero en su Historia de la Baja o Antigua California de 1789 se sirve ampliamente de la Historia natural y Crónica de la Antigua California de su hermano en Cristo de la provincia de la Nueva España, Miguel del $\mathrm{Barco}^{3}$, quien, a diferencia de él, conocía la península por haber servido treinta años en ella como misionero. Sin embargo, para lograr el máximo de exactitud en las descripciones de partes de la península con sus habitantes, sus idiomas y costumbres, la flora, la fauna, el clima o su misma forma, el padre del Barco cita los apuntes-diarios, descripciones y otros escritos de aquellos compañeros suyos que reconocieron, observaron etc. diferentes partes o fenómenos y en base a esta experiencia describieron determinado asunto. Puesto que tanto del Barco como Clavigero redactaron sus obras en el exilio, desprovistos ya de los archivos de la provincia jesuítica de la Nueva España, y puesto que su finalidad era combatir la demonización de todo lo americano, entonces viva en una parte de las publicaciones en la Europa del Siglo de las Luces, echaban mano de las descripciones e informes publicados por la misma Compañía en Europa antes de la expulsión. Así del Barco, como prueba irrefutable de la peninsularidad de California, no se limita a sintetizar lo que era una especie del saber común sobre el tema dentro de la Compañía en base a los reconocimientos de varios padres, sino que cita y comenta el Derrotero del viage que en descubrimiento de la costa oriental de Californias hasta el río Colorado, donde se acaba su estrecho, hizo el padre Fernando Cónsag,[...] por orden de el Padre Christóval de Escobar y Llamas, provincial de Nueva España, redactado en 1746 y publicado íntegro en Madrid en 1757 en un informe sumario sobre Califor$\mathrm{nia}^{4}$. La regla de basar historias en los testimonios, discursivamente menos exigentes pero fehacientes, se mantuvo entre los autores jesuitas como principio metodológico también en circunstancias adversas al cultivo de los métodos empíricos. Si nos detenemos en el destino del Derrotero de Consag, nos damos cuenta de que este, como tantos otros informes y descripciones redactados en los páramos californianos fue publicado casi al ser recibido en la cabeza de la provincia: íntegro en 1757, tres veces más en versiones abreviadas y modificadas en la Península y

2. Nos referimos a la bien conocida convicción de que «a la diestra mano de Indias» se encontraba tierra desconocida poblada por las Amazonas (que en sus variantes anteriores equivalía a una isla). Existen muchos indicios del peso del imaginario de los descubridores y conquistadores del siglo XVI entre los del siglo XVIII: mencionemos aquí el título de un informe del padre Cardiel sobre el viaje de exploración de la Patagonia: Carta del Padre jesuita José Cardiel, escrita al señor gobernador y capitán general de Buenos Aires sobre los descubrimientos de las tierras patagónicas en lo que toca a los Césares (17 de agosto de 1746)

3. A pesar de ser citado como fuente para la Historia de Clavigero durante su redacción en el destierro italiano y del gran mérito que esta síntesis tiene, la obra del padre del Barco, archivada en el Fondo Gesuitico de la Biblioteca Nazionale Vittorio Emmanuele II en Roma, fue publicada por Miguel León-Portilla apenas en 1988, bajo el título mencionado, en la edición de la UNAM en México.

4. Era la Noticia de California y de su Conquista Temporal y Espiritual hasta el Tiempo Presente de Miguel Venegas y Andrés Marcos Burriel publicada en Madrid. 
en Ultramar en el lapso de 25 años, y traducido a cuatro idiomas ${ }^{5}$, comprobando el interés por la «información virgen» ${ }^{6}$ que aportaban.

Carta edificante, o carta de edificación, una especie de necrologio que los miembros de la Compañía escribían acerca de un hermano fallecido de costumbre corresponde a presentaciones tan elaboradas de la vida de los fallecidos que más parecido tienen con biografías propiamente dicho que con cartas, por largas que estas puedan ser. Al mismo tiempo, describiendo la vida del misionero con todos los pormenores, especialmente aquellos que destacaban sus esfuerzos de peregrino en busca de grey y descubridores de partes antes desconocidas, en la carta edificante se proporcionaba información muy parecida a la del informe o la descripción. María Eugenia Ponce Alcocer en su estudio preliminar a la transcripción de la carta edificante escrita por el mencionado padre Consag sobre su hermano en Cristo Antonio Tempis recuerda que el origen de este género se da en la idea del fundador de la Compañía, San Ignacio, al insistir en el intercambio de información entre los miembros en forma de «epistolario misionero»:

En la carta del fundador de la Compañía de Jesús escrita a su compañero jesuita Pedro Fabrio, en Roma el 10 de diciembre de 1542, insistió en que en esas cartas llamadas principales, los soldados de Cristo debían dar noticia de su labor pastoral, que había de ser edificante. Estas cartas tuvieron una función biográfica y apologética; fueron textos escritos para exaltar las virtudes humanas de los miembros de la Compañía puestas al servicio de Dios, y debían ser un ejemplo para sus integrantes. Al fallecer el jesuita, su vida ejemplar debía difundirse, con ese propósito eran escritas por el Superior o por el hermano en Cristo que más lo conoció, y posteriormente, se enviaban copias a los demás, con la intención de que se imitaran sus virtudes; en estos casos, la carta principal pasaba a llamarse carta edificante?.

Sin embargo, con el paso del tiempo a las cartas edificantes se les fueron adscribiendo tareas adicionales impuestas por las circunstancias del momento. La primera fue la de incitar a los jesuitas europeos jóvenes que las leyeran a pedir puestos en misiones ultramarinas dada la falta crónica de misioneros en comparación con las proporciones del proyecto misional. Este papel propagandístico contaba con el efecto que la presentación de los aspectos martiriales de la vida del misionero pudiera tener en el jesuita joven, por regla deseoso de morir como mártir. La segunda también era de índole propagandística: dado lo profuso del escrito, que contenía

\footnotetext{
5. El manuscrito del texto se conserva en la Beinecke Library de la Universidad de Yale (Collection of Western Americana), y las dos copias del mismo en el AGI de Sevilla y en la Biblioteca Nacional de México (ver Peter Gerhard, The North Frontier of New Spain). En el siglo XVIII el Derrotero fue publicado en varias formas en recopilaciones de testimonios sobre el noroeste novohispano, y la Noticia de VenegasBurriel fue traducida al inglés en 1759 como A Natural and Civil History of California, y a partir de esta traducción se hicieron las traducciones al francés, alemán y holandés en pocos años (ver Henry Raup Wagner, The Spanish Southwest 1542-1794. An Annotated Bibliography). Mencionamos estos datos a título de ejemplo de la demanda de testimonios sobre lo americano en España y en el resto de Europa. 6. Presto la expresión de Ignacio del Río, 1990, p. 13.

7. Ponce Alcocer, 2005, p. XVII. El título completo de la publicación de la transcripción editada paralelamente con la publicación original del año 1748 es Carta del P. Fernando Consag de la Compañía de Jesús Visitador de las Misiones de Californias a los Padres Superiores de esta Provincia de Nueva España.
} 
elementos de descripciones de exploraciones encargadas a los padres misioneros, de la vida diaria de la misión así como del ámbito natural, la mayor parte de las cartas edificantes proporcionaban información interesante para el potencialmente numeroso lectorado de la época, y la Compañía veía en esta amalgama de lo edificante con lo informativo una vía para combatir indirectamente la fama que se había creado sobre las misiones como centros que recogían metales y piedras preciosas para los arcanos de su orden y para el rey sin tener que recompensar por ello de forma alguna a los indios reducidos, sometidos incondicionalmente al misionero. En su esfuerzo de construir la imagen completa del enseñoramiento jesuita de California, tierra que, por demás, los jesuitas creían prometida y reservada para ellos por la Providencia, Peter Masten Dunne en su Black Robes in Lower California se remite a las cartas edificantes junto con otras fuentes justamente para recoger datos sobre lo diario y elevarlos al nivel de proezas. Sirviéndose admirablemente de las imágenes así reconstruidas para ofrecer la visión del conjunto que se presenta como resultado de la única compaginación de esfuerzo personal y visión general, envuelve la figura del misionero con un espíritu triunfalista8:

Ugarte filled up a gorge to make a trail, using 22.000 loads of rock and 18,000 of earth carried by the first mules he possessed. He built a dam to distribute the waters of the thinly flowing stream [...] By his labors Ugarte made another oasis of fertile soil amidst the baking rocks of the peninsula. For his Indians he converted sterile, cactus-ridden patches of land into habitable places for man?.

Sin estar exenta de notas de triunfalismo parecidas a las del libro de Dunne, la carta edificante de costumbre pone hincapié en el sacrificio y en la disciplina, de forma que la figura del misionero, sin dejar de ser superior al conjunto del ambiente y no solo a los indios, a menudo gracias a sus conocimientos tecnológicos, es en primer lugar la de siervo de Dios que cumple a diario con su tarea de misionero y arquitecto del ideal social que las misiones debían poner en práctica. Para lograrlo, es capaz de sobrellevar cualquier dificultad y pena. Estas características sitúan esta práctica escrituraria en el marco de la literatura «a la antigua», cuyo interés primordial era su utilidad moral y social. Veamos un ejemplo:

y en todas sus cosas mostró su aprecio a la santa pobreza, cuyos efectos suavizaba con sus usados refranes: Todo trabajo por amor de Dios. [...] Y no hay que admirar, que su reverencia alcanzará tantas bendiciones del cielo en lo temporal, cuando en esto no buscaba más logro, que el bien del próximo, para quien era todo caridad. Hallaban todos en el Padre Antonio, lo que habían menester así para sus almas como para sus cuerpos: los pecadores afabilidad, y consejo: los tibios

8. A título de ejemplo, mencionamos el capítulo XIII, «Ugarte builds a ship», para el que se basa, entre otras fuentes, en Vida y virtudes de el venerable, y apostólico padre Juan de Ugarte, impresa en el Real y Más Antiguo Colegio de San Ildefonso en México en 1752 (edición reciente por Gale Sabin Americana, 2012).

9. Dunne, 1968, p. 170. 
alientos; los afligidos consuelo; los desvalidos refugio: los perseguidores amparo; los menesterosos socorro ${ }^{10}$.

Mientras que las descripciones de exploraciones y observaciones de todo tipo así como las cartas edificantes se redactaban con propósitos prácticos inmediatos y para estos propósitos se publicaban, las cartas que aquí denominaremos «personales»-aunque no lo fueran en el sentido que hoy se entiende bajo el término y concepto de correspondencia personal - estaban destinadas a los contactos individuales de los miembros de la Compañía, sobretodo los misioneros entre ellos, pero también con los miembros de la Compañía de sus antiguas provincias (especialmente los misioneros llamados «germanos», es decir centroeuropeos) o -menos- con sus familias. Se trata de un cuerpo enorme de escritos heterogéneos desde el punto de vista de su contenido que últimamente ha atraído la atención de los investigadores de manera que su corpus sigue creciendo. Diferenciamos estas cartas de otro corpus muy nutrido, el de las cartas que los miembros de la Compañía de Jesús, mayormente extranjeros, enviaban a sus antiguas provincias con las descripciones de las partes del Nuevo Mundo que les tocaron vivir y servir y cuyo fin primordial era eso: la descripción de lo que el destinatario desconocía acompañado por los comentarios y explicaciones. Buena parte de ellas se conoce hoy en la forma en que fueron publicadas en los periódicos de la época en otros idiomas, es decir, no castellano sino en francés (Lettres édifiantes et curieuses ecrites des Missions Etrangeres par quelques Missionaires de la Compagnie de Jesus) y en alemán (Der Neue Welt-Bott mit Allerband Nachrichten dern Missionarum Soc. Jesu). Puesto que se trata de un corpus separado y diferente de las cartas que aquí nos interesa presentar, y por ser muy citadas y comentadas su inclusión sobrepasaría el formato del presente trabajo, aunque desde varios puntos de vista pueden agregarse a las formas discursivas que presentamos.

\section{EMERGE EL DORSO DEL PROYECTO GRANDIOSO. ¿QUÉ HACER CON ÉL?}

Las cartas personales, diferentes de las cartas oficiales que estaban obligados a escribir a las personas de rango más alto que el de ellos a lo largo de su trabajo misional y que han sido aprovechadas tanto por la investigación reciente como por las de larga data, y que se enviaban mutuamente, permiten conocer lo que el discurso oficial por su misma calidad de oficial no mencionaba, o bien, lo decía de forma distinta. Su lectura deja entrever el dorso de la vida día a día del sistema al que todos ellos contribuían y que, apreciado a través del gran narrativo que este formó acerca de sí mismo, no se percibía. Las cartas escritas con finalidad práctica dejan ver cómo un padre solo, rodeado de hasta 7000 indios, de verdad lograba mantener el sistema implantado en la misión ${ }^{11}$ :

10. «Carta edificante sobre la vida del misionero Antonio Tempis», escrita por Fernando Consag en 1748. Citamos por la transcripción moderna de la misma hecha por $\mathrm{M}^{\mathrm{a}}$ Eugenia Ponce Alcocer en la edición citada anteriormente.

11. Resulta interesante cotejar el episodio que se menciona en nuestra cita con la descripción de la rutina diaria en la misión tal y como la presenta José Cardiel en su «Declaración de la verdad» de 1758 que 
Cuando vinieron acà ultimamente los vinateros de San Estanislao, vinieron entre ellos dos moços naturales deste Pueblo huidos yà años hà. Diòme aviso de ello un Cabildante Cacique de uno delos dos, y su pariente, haziendome acordar al mismo tiempo el inconveniente muy perjuizial à este Pueblo, que hay en valerse los Padres del Taruma de semejantes Yndios para los despachos de alli acà. [...] determinème a dar orden, y lo di de prender a los dos haziendolos meter en grillos sin mas castigo... ${ }^{12}$

Mientras que el gran narrativo por su misma índole no puede reparar en los sentimientos íntimos de descontento, soledad, injusticia, etc. causados por las relaciones personales a menudo teñidas por preferencias vinculadas con el origen de los misioneros, las cartas presentan una fuente preciosa para conocer este aspecto de la vida del misionero. Al mismo tiempo, este tipo de información echa luz adicional a la jerarquía existente dentro de la Compañía. Así el padre Marqueseti en otra carta al visitador Contucci menciona la actitud adversa de los padres de origen español hacia los jesuitas extranjeros:

Escriviòme como à tal el Padre Pifferetti despues de removido de su Curato, yà dos cartas, en que, despues de significarme su afliccion, que dize es tan grande, que està yà cerca de acabarle la vida, me ruega por la sangre de lesuChristo, que escriviendo à Vuestra Reverencia con eficacia procure moverle con su informe à boluer por su inocencia, haziendole Vuestra Reverencia justicia [...] se sabe de ambos (delatores, aut.) que ademas de ser nimios en molestar con delaciones alos Superiores, son en esos menos veridicos ò por inconsiderados, ò por desafectos, como consta lo son alos estrangeros ${ }^{13}$.

La animadversión de los misioneros españoles hacia los extranjeros, se menciona de forma oblicua en la carta que en 1751 el padre Consag, de origen croata, envía de su misión de San Ignacio en Baja California a México al padre Göbel, germano y hermano en Cristo de la misma provincia de Austria. La parte más delicada de su contenido (que aquí citamos) originalmente fue escrita en alemán. A la vez que el tema de la ojeriza entre los dos grupos, el padre toca uno de los temas centrales en la vida del misionero, y es el de su adaptación a otra cultura, tema que el gran narrativo esquiva en favor de la tematización de la imposición de la cultura dominante en el espacio fronterizo y la aculturación de sus habitantes aborígenes como su deseada consecuencia:

posteriormente, para la publicación, reviste el título Las misiones del Paraguay (Cardiel, 2002).

12. Parte de la carta del misionero Juan Bautista Marqueseti al visitador Nicolás Contucci escrita en la misión de Nuestra Señora de Fe, en Paraguay, el 30 de septiembre de 1762. (Archivo General de la Nación, Buenos Aires, 9.6.10.5. 9h). La correspondencia de Marqueseti encontrada en el AGN, fue transcrita y traducida junto con la correspondencia de otros misioneros de aquellas partes de la antigua provincia de Austria que forman parte del moderno estado de Croacia y publicada en el libro intitulado Paragvajska pisma, por Mirjana Polić Bobić y Mijo Korade). Tanto en la transcripción de esta como de otras cartas y el resto de los escritos preferiimos mantener la grafía del original, sin adaptarla al uso moderno, porque creemos que las características de la expresión escrita de los autores en sí representa información.

13. AGN Buenos Aires, 9.6.10.6. 10f, Paragvajska pisma, pp. 146-148. 
Verdaderamente el que busca otra cosa en las Indias que servir à lesucristo, vivirà muy desconsolado, y en donde pensaba se podía salvar mas fácilmente, esta mas arriesgado a perderse. Como nosotros extranjeros venimos por servir a lesuchristo, y padecer por amor suio, y a imitación suya, nunca nos emos de olvidar de esta primera intención que tuvimos, por lo qual es menester oir y no oir, esto es dejo entrar por un oído y por el otro salir, ver y no ver, esto es, mirar la cosa aunque nos iera y cause dolor, como cosa que se egecuta en otros, y para vivir con algún sosiego olvidarse de todos los estilos de alla y acomodarse a los de acà, por que según son las Naciones y Genios distintos ${ }^{14}$.

En las cartas se mencionan acontecimientos extremos e indeseables: fugas de misioneros como consecuencia de desobediencia de todas las reglas de conducta y de los votos tomados. Los ejemplos son numerosos y entre sí variados y curiosos, pero dada la manera oblicua de cómo los misioneros formulan sus observaciones, el descifre de lo ocurrido en sí resulta arduo, y dado que rara vez una carta contiene la información completa expresada de forma directa, de costumbre ofrece tan solo algunos elementos para la reconstrucción de la totalidad de un caso, y quizás otros tantos para el análisis de las actitudes para con él: por ejemplo, en las cartas intercambiadas entre los padres misioneros Arriola, Alvarez y Consag (sirviendo unos en Sinaloa y otros en Baja California) así se comenta el caso del padre sinaloense Domínguez, que aparece de forma marginal en las cartas de otros misioneros de la misma época ${ }^{15}$. Bernd Hausberger en su estudio de la vida cotidiana de los misioneros en el noroeste novohispano menciona temas al parecer tan sorprendentes y encontrados en ellas como lo es la locura ${ }^{16}$ como consecuencia del miedo de los «indios, españoles y bestias salvajes», amén de una verdadera serie de fenómenos, situaciones y acontecimientos cotidianos que permiten reconstruir no el conjunto, sino los fragmentos sintomáticos del conjunto: la vida en la oscuridad por falta de velas, con relojes descompuestos o con gafas rotas sin posibilidad de componerlos, curación de enfermedades con medicinas indígenas sabiendo que la apropiación de los modelos indígenas de vida de cualquier índole no se permitía, etc.

De los tres grupos de textos, el que - de ser cotejados todos sus ejemplos-mayor uniformidad presentara sin duda sería la carta edificante, por su contenido, por los elementos que la componían, por la actitud del que narra la vida de su hermano en Cristo, por el espíritu que transmitía, por la visión de la misión de aquel cuya vida se presentaba así como también por un estilo específico y reconocible, siendo la

14. La copia de la carta se encuentra en British Library Add. 13986, fol, 297r-302v, sin paginación. De reciente traducción al idioma materno del padre Consag se encuentra en Mirjana Polić Bobić, 2015, pp. 196-199.

15. Las cartas se encuentran archivadas en la Colección de manuscritos de la Antigua Provincia de la Compañía de Jesús en la biblioteca Francisco Xavier Clavigero de la Universidad Iberoamericana en la Ciudad de México, bajo los números 147 y 148 y, según nuestras informaciones, no han sido publicadas. 16. La mención de locura como una de las reacciones a la dura vida en las misiones novohispanas remite al estudio de un caso famoso de pérdida de juicio en el noroeste novohispano: el del visitador conde de Gálvez, ocurrido en la misión de Ures en Sonora, cuyos testigos fueron silenciados por la autoridad virreinal obviamente por lo embarazoso que era para el gobierno (Ver Ignacio del Río, 2007, pp. 49-74). Es de suponer que un estudio de este fenómeno entre los misioneros daría resultados interesantes. 
mayor diferencia la extensión de la carta. Los otros dos acusan diferencias notables en cuanto a la extensión, estilo (los textos de los jesuitas extranjeros, a menudo conteniendo información primorosa de sus propias exploraciones, resultan poco claros por el uso específico que daban a ciertas voces y expresiones castellanas) y otras características: en los informes, el orden de presentación, la capacidad de introducir un sistema en ella, la formación del misionero adquirida anteriormente, sus conocimientos específicos, etc. Las cartas personales por otra parte, además de las figuras retóricas empleadas en la parte inicial y final, las formas de cortesía y titulaciones adecuadas para el destinatario y los cargos de las personas en ellas mencionadas, podían variar y de hecho, de los tres grupos, son los que presentan información menos seleccionada, a menudo sorprendente e incluso contradictoria. Sin embargo, lo que tienen en común los tres y lo que da pie a este intento de agruparlos es la presentación de información «virgen», a veces sin otra refinación que la que requiere la misma verbalización, y que permite una reconstrucción de las situaciones en las fronteras a la época, posiblemente diferente de la que ofrece el gran narrativo. Teniendo en cuenta que el proyecto misional jesuita en el Nuevo Mundo y en el Oriente fue y sigue siendo uno de los proyectos más debatidos en la historia moderna del Occidente, es de suponer, y la historiografía lo está comprobando, que el imaginario creado en el seno de los detractores del proyecto misional y lanzado desde allí también encontraría detalles interesantes que cotejar con él. La posibilidad de reconstruir el largo y penoso proceso del encuentro de culturas en base a la relectura de lo apuntado en el terreno permite asomarse -como se ha visto en los ejemplos mencionados de fragmentos de cartas personales- a las vidas de los agentes de este encuentro y de los procesos, en primer lugar mentales, que allí se realizaban. En su estudio de las reinvenciones del pasado español en el vasto espacio que denomina «la frontera española en América del Norte» por parte de estudiosos estadounidenses, David Weber dice que «...la herencia española en Norteamérica no es solo lo que hemos imaginado que es, sino también lo que sigamos haciendo con ella» ${ }^{17}$.

A la luz de ello, cabe suponer que las (re)lecturas de los géneros presentados para los entendidos en el tema no ofrecen oportunidades de descubrimientos revolucionarios ni, por consiguiente, de cambios revolucionarios de la imagen que ya han formado sobre el conjunto de que ellos informan. Sí ofrecen, al contrario, material para su enriquecimiento o, si queremos, su depuración, procesos de todo punto igualmente exigentes. Uno de los campos quizás más interesantes, dada su vinculación con la creación artística y literaria de las épocas en que se produjeron los textos que aquí nos conciernen es el imaginario de sus autores así como de los que estos de una u otra forma presentan.

17. Nuestra cita es del último capítulo de su libro La frontera española en América del Norte, intitulado «Herencia española e imaginación histórica» (p. 505), en que pasa revista y comenta los modelos de «reinvención» del pasado español que abarcan desde su romantización e idealización hasta la aplicación incondicional de la leyenda negra a toda consideración de esta herencia, destacando las metas de cada una así como trampas y posibilidades que supieron evitar o aprovechar hasta alcanzarlas. 
En este sentido en las relecturas pueden buscarse puntos en común, o bien los que hacen diferencia, entre el imaginario de los conquistadores y misioneros del tiempo de la conquista y los de los siglos posteriores, y de esta forma contribuir a los debates sobre su resistencia a los cambios o bien sobre las modificaciones que sufrieron con el paso del tiempo. Luis Weckmann en su clásico La herencia medieval de México entre el caudal de los ejemplos que ilustran su tesis de la fuerte presencia de lo medieval en la época colonial cita al jesuita e historiador Francisco Florencia quien a finales del siglo XVII «...asegura que las voces angélicas anunciaron por los aires, para ahuyentar a los demonios, la llegada de la Compañía de Jesús a la Nueva España» ${ }^{18}$. Esta convicción de los jesuitas, en que el historiador mexicano reconoce una de las señales de la presencia del espíritu medieval en el siglo del barroco, independientemente de su raíz medieval, a los ojos del re-lector de algunas descripciones dieciochescas de aquel territorio va de la mano con las imágenes que allí se encuentran (independientemente de que sean en parte fidedignas de la situación «objetiva») y que, mutatis mutandis, remiten a lo terrible o bien a lo maravilloso del imaginario sobre tierras y mares desconocidos, y sobre todo de sus márgenes, cultivadas por el explorador del XVI, que sin duda llevan también su carga de lo medieval. Mencionemos aquí la descripción de la línea divisoria entre el golfo de California y el océano Pacífico como lugar en que nadan «gran cantidad de culebras medianas y sirven de seña que ya se llegó al seno», o la convicción de que todos los rumiantes que cazan los indios por los despeñaderos de la sierra californiana tienen en su estómago piedra bezoar, desde antiguo apreciada como panacea universal, descripciones que aparecen en los apuntes sobre la exploración de partes de Baja California ${ }^{19}$. Hausberger cita la descripción de la culebra hecha por el padre Marco Antonio Kappus a su hermano, y que contiene clara alusión a un proceso de simbiosis del animal con el dragón, uno de los seres terribles que según los estudios del imaginario de los navegantes de los fines del XV y comienzos del XVI poblaban las desconocidas y peligrosas márgenes del mundo: «Que en América se encuentran más y mayores serpientes que en Europa ya es conocido [...] unas se hacen tan gordas que apenas un hombre las puede abrazar [...] son tan tratables [...] lo que me dio valor de tomar con mis manos a tal dragón en varias ocasiones» ${ }^{20}$.

18. Citamos por Weckmann, vol I, p. 288, por no tener al alcance la Historia de la Provincia de la Compañía de Jesús en la Nueva España (1694). La cita representa tan solo una de las pruebas de la convicción de los miembros de la Compañía de que California, tierra imposible de conquistar, estaba reservada para que ellos la evangelizaran, y de esta manera, sometieran al «suave yugo de la fe» como decían (ver Ignacio del Río, 2003, cap. I, «La California jesuítica: una provincia misional», pp. 21-94.

19. Las citas son, respectivamente, de la Descripción compendiosa de lo descubierto y conocido de la California del p. Consag (British Library, Egerton Mss 1797, publicada en formas abreviadas y modificadas en varios libros en el siglo XVIII) y del «Diario del viaje que hizo el padre Fernando Consag de la Compañía de Jesús en la California desde 27 grados, y 2 terzios entre la Sierra Madre y el Océano»,(en Apostólicos afanes de la Compañía de Jesús, Barcelona, 1754)

20. El trabajo de Hausberger, del que citamos, Hausberger, 1997, pp. 91-92, en base a la lectura de gran número de cartas presenta de forma sintetizada las actitudes y las formas de conducta que considera sintomáticas en cuanto a los segmentos importantes como lo son la naturaleza, los indios, la alimentación etc, pero también los sentimientos íntimos que considera paradigmáticos entre los misioneros de aquella provincia. 
Aquel segmento de la vida misionera que en la investigación se define como expectativas del medio al que fueron enviados los misioneros y las diferencias entre estas y las posibilidades de realización de su tarea evangelizadora, pero también conquistadora y de aculturación, atañe todos los aspectos de su conducta y percepción. La misión como forma de actuación de la Compañía de Jesús sobre un territorio ${ }^{21}$ en la época ya tardía del virreinato implicaba, por el mismo hecho de situarse en la frontera con la otredad cultural y religiosa así como racial y social, una situación parecida a aquella experimentada en los tiempos de las primeras conquistas y reconocimientos de los nuevos territorios y de la evangelización inicial que las acompañaba. A partir de ello, se plantea la pregunta acerca de las formas de pensar, vivir y actuar, o de lo que Cardiel llama «el porte temporal y espiritual de los Misioneros $»^{22}$ en una situación que requiere las formas conocidas desde el Quinientos. Por todo ello, la lectura de los corpus que aquí presentamos puede ser instructiva acerca de la perduración, o larga duración (en el sentido braudeliano) de los grandes temas del siglo XVI en las mentalidades de los misioneros del siglo $X V I I I$. Uno de ellos es el tema que en otro texto ${ }^{23}$ he definido como "dos tiempos»: por una parte el misionero jesuita se esforzaba en crear, con los indios reducidos, una comunidad de creyentes en que el modelo y el orden deseado, una vez establecido, se perpetuaría y cultivaría, evitando todo cambio salvo el del número de almas y territorios para reducirlas, porque «...(nuestras) perlas son las almas de los indios» (Consag en la carta a Göbel); tal comunidad estaba ideada para vivir más de acuerdo con el ideal medieval ora et labora dando la espalda al mundo en cuyas fronteras se situaba, y contrariando de esa forma su acentuado materialismo del que participaba también el clero urbano, tanto regular como seglar ${ }^{24}$. Por la otra, sin embargo, la comunidad de misioneros involucrados en este proyecto forzosamente tenía que mantener el contacto con el mundo de fuera, con los centros de sus provincias, con sus antiguas provincias, etc. Aunque pidieron y aceptaron el papel de una ruedecita en el mecanismo creado para funcionar a nivel global, y trabajaban en las meras

21. La acepción que con mayor frecuencia hoy día se le da al término «misión» en los estudios americanos es el de la organización territorial para el misionero y los indios reducidos. Sin embargo, es tan solo una de las tres acepciones que la noción tenía para los jesuitas de los tiempos de las misiones, siendo las dos restantes el envío personal y la actividad en el lugar donde el enviado realiza esta actividad. Cabe también recordar que en aquel entonces, en los comienzos de los planes de la labor apostólica fuera de Europa, el término surgió como neologismo sustituyendo un conjunto de expresiones. En su trabajo «Conquistar todo el mundo: los fundamentos espirituales de las misiones jesuíticas» Michael Sievernich S.J. explica la nueva terminología, creada en función del programa de la naciente Compañía de Jesús,en Sivernich, 2007, pp. 3-23.

22. Cardiel, 2002, p. 102.

23. Ver «La concepción del tiempo entre los misioneros de la colonia tardía», 2012, vol. 2, pp. 243-255.

24. En una de las cartas del ya mencionado padre Marqueseti encontramos el ejemplo de la modestia del misionero: encargo de telas muy modestas para su propia indumentaria: «Y le ruego tambien, que valiendose de la misma ocasion, me favorezca assimismo con remitirme Vuestra Reverencia por su parte alguna ropa de la tierra con un paño y algunas sempiternas y bayetas de Castilla..».(AGN Buenos Aires, 9.6.10.5 9b, Paragvajska pisma, p. 124). Phillip Caraman en su libro The Lost Paradise habla sobre el desdén de los misioneros de la Provincia del Paraguay por la riqueza que tenía acumulada el clero limeño. Paul Ganster en su estudio «Religiosos» habla sobre el materialismo del clero colonial, en Ganster, 1992, pp.141-174. 
márgenes de él, se mostraban curiosos de estar al tanto de las experiencias de los misioneros en otras partes de la colonia (Hausberger menciona el carteo de los misioneros novohispanos con los de las Filipinas) o bien de Europa («Los mas de los PP. somos amantes de las noticias Europeas, y qualquiera noticia tocante a la Compañía para mi es muy apreciada» escribe el padre Consag al padre Göbel).

La idea misma de la creación de una sociedad nueva y ejemplar, desprovista de los vicios de las sociedades de origen de los misioneros, es heredera de los sueños y proyectos utópicos del siglo XVI. Todos los que postulaban para las misiones indianas compartían el eco de ellos. Las formas discursivas mencionadas ofrecen la posibilidad de analizar las diferencias entre estas ideas iniciales, posiblemente no siempre claras y seguramente sujetas a idealizaciones, y la realidad, y, por otra parte, la conciliación con la situación en el terreno en que había que ganarse la confianza de los indios y comenzar a actuar. ¿Cómo conciliaban íntimamente y en la práctica diaria las ideas preconcebidas con las situaciones que encontraban en el terreno? Las tres variantes de este nuestro «narrativo menor» presentan rico caudal para la reconstrucción de la lucha diaria con ese hiato. Otro ideal que impulsaba a los misioneros a actuar, el del martirio, que de verdad experimentaron pocos, y al que se acercaron muchos en los trances diarios que les deparaba la vida en aquellas partes inhóspitas, se menciona en muchas cartas edificantes, y las menciones de experiencias extremas en las cartas personales dan la razón a las relecturas a partir de ese momento de suma importancia en la mentalidad del misionero.

\section{CONSIDERACIONES FINALES}

Los espacios fronterizos por definición son productores de formas nuevas que resultan del contacto de culturas: mencionando algunos productos de las culturas de los indígenas que desde antiguo habitan la amplia franja de los dos lados de la frontera entre México y los Estados Unidos, David Weber nos hace recordar que, a diferencia de la opinión común, no se trata siempre de formas auténticas, es decir pre-misionales, sino de productos del contacto entre las comunidades indígenas y las artes europeas que allí introdujeron los misioneros. Del mismo modo, las formas de pensar y actuar de una de las dos partes involucradas - la de los misioneros - tomando formas imprevistas para lograr su meta, a la larga llevaban a usos que desde el centro de sus provincias o centros urbanos en general muy probablemente se calificarían de impuras o inadmisibles. Releídos desde este punto de vista, los testimonios de lo vivido a la vez lo son de los comienzos y los orígenes del lento proceso de construcción de lo que son las sociedades existentes en esas tierras hoy en día.

Al comienzo de este trabajo hemos partido de la suposición de que la relectura de las formas discursivas que hemos definido también como «narrativo menor» puede abrir pistas para el conocimiento de aquellos aspectos de la vida de las misiones en las fronteras del mundo hispano que el gran narrativo descuida. Las propuestas de relecturas temáticas aquí expuestas permiten, a nuestro juicio, la percepción de lo fragmentario, subjetivo y callado de un grandioso proyecto. Indudablemente, las 
relecturas que parten de tales premisas están teñidas por las sensibilidades de hoy y marcadas por las tendencias recientes de investigar los segmentos menos trabajados del patrimonio literario colonial, así como fenómenos marginales e híbridos. Sin embargo, su finalidad no es otra más que la de «redondear» o en todo caso corregir las imágenes ya existentes de un fenómeno complejo del pasado que, por su peso en la formación del presente, no deja de intrigar.

\section{BIBLIOGRAFÍA}

Apostólicos afanes de la Compañía de Jesús escritos por un padre de la misma sagrada religión de su provincia de México, Barcelona, Pablo Nadal, Impressor en la calle de la Canuda, 1754.

Barco, Miguel del, Historia natural y Crónica de la Antigua California, ed. Miguel León-Portilla, México, UNAM, 1988.

Caraman, Phillip, The Lost Paradise. The Jesuit Republic in South America, New York, The Seabury Press, 1976.

Cardiel, José, Las misiones del Paraguay, Madrid, Dastin Historia, 2002.

«Carta del padre José Cardiel, escrita al señor gobernador y capitán general de Buenos Aires, sobre los descubrimientos de las tierras patagónicas, en lo que toca a los Césares (11 de agosto de 1746)», en Derroteros y viajes a la Ciudad Encantada o de los Cesares, que se creía existiese en la Cordillera, Al sud de Valdivia, Buenos Aires, Imprenta del Estado, 1835, pp. 11-19.

Clavigero, Francisco Xavier, Historia de la Baja o Antigua California, Madrid, Porrúa, 2007.

Dunne, Peter Masten, Black Robes in Lower California, Berkeley/Los Angeles, University of California Press, 1968.

Ganster, Paul: «Religiosos», en Ciudades y sociedad en Latinoamérica colonial, México, FCE, 1992, pp. 141-174.

Gerhard, Peter, The North Frontier of New Spain, New Jersey, Princeton University Press, 1982.

Hausberger, Bernd, «La vida cotidiana de los misioneros jesuitas en el noroeste novohispano», Estudios de la historia novohispana, 17, 1997, pp. 63-106.

Polić Bobić, Mirjana, Kalifornijski zapisi oca Ferdinanda Konšćaka iz Družbe Isusove, Zagreb, Hrvatska sveučilišna naklada, 2015.

Polić Bobić, Mirjana, «La concepción del tiempo entre los misioneros de la Colonia tardía», Verba hispánica, 2, 2012, pp. 243-255.

Polić Bobić, Mirjana y Mijo Korade, Paragvajska pisma, Zagreb, Matica hrvatska, 2015. 
Ponce Alcocer, María Eugenia, Carta del P. Fernando Consag de la Compañía de Jesús Visitador de las Misiones de Californias a los Padres Superiores de esta Provincia de la Nueva España, México, Universidad Iberoamericana, 2005.

Río, Ignacio del, A la diestra mano de las Indias. Descubrimiento y ocupación colonial de la Baja California, México, UNAM, 1990.

Río, Ignacio del, El regimen jesuítico de la Antigua California, México, UNAM, 2003.

Río, Ignacio del, El Noroeste del México Colonial, México, UNAM, 2007.

Sievernich, Michael S J, «Conquistar todo el mundo: los fundamentos espirituales de las misiones jesuíticas», en Desde los confines de los imperios ibéricos. Los jesuitas de habla alemana en las misiones americanas, ed. Karl Kohut y $\mathrm{M}^{\mathrm{a}}$ Cristina Torales Pacheco, Frankfurt/Madrid, Vervuert/Iberoamericana, 2007, pp. 3-23.

Venegas, Miguel y Andrés Marcos Burriel, La Noticia de California y de su Conquista Temporal y Espiritual hasta el Tiempo Presente, Madrid, Imprenta de la Viuda de Manuel Fernández y del Supremo Consejo de la Inquisición, 1757. Reimpreso en México por Luis Alvarez y Alvarez de la Cadena, 1944.

Villavicencio, Juan Joseph de, Vida y virtudes de el venerable, y apostólico padre Juan de Ugarte, México, Imprenta del Real y más Antiguo Colegio de San IIdefonso, 1752.

Vogeley, Nancy, «Introducción» a Historia de la literatura mexicana, coord. Beatriz Garza Cuarón, vol. 3, México, Siglo XXI, 2011, pp. 13-33.

Wagner, Henry Raup, The Spanish Southwest 1542-1794. An Annotated Bibliography, Albuquerque, The Quivira Society, 1937.

Weber, David J., La frontera española en América del Norte, México, FCE, 2000.

Weckmann, Luis, La herencia medieval de México, México, El Colegio de México, 1984. 
